\title{
Pacemaker or no pacemaker? The question of a lifetime
}

\author{
Carlos M. Mery, MD, MPH, ${ }^{\mathrm{a}}$ and Daniel P. Shmorhun, $\mathrm{MD}^{\mathrm{b}, \mathrm{c}}$
}

From the ${ }^{a}$ Division of Pediatric and Congenital Cardiothoracic Surgery, Department of Surgery and Perioperative Care and ${ }^{\mathrm{c}}$ Department of Pediatrics, University of Texas Dell Medical School, Dell Children's Medical Center, Austin, Tex; and ${ }^{\mathrm{b} C h i l d r e n ' s ~ C a r d i o l o g y ~ A s s o c i a t e s, ~ A u s t i n, ~ T e x . ~}$

Disclosures: Authors have nothing to disclose with regard to commercial support.

Received for publication Oct 18, 2018; accepted for publication Oct 20, 2018; available ahead of print Dec 14, 2018.

Address for reprints: Carlos M. Mery, MD, MPH, Dell Children's Medical Center, Center for Pediatric and Congenital Heart Disease, 4900 Mueller Blvd, Suite 3S.003, Austin, TX 78723-3079 (E-mail: cmery@ austin.utexas.edu).

J Thorac Cardiovasc Surg 2019;157:1180-1

$0022-5223 / \$ 36.00$

Copyright (c) 2018 by The American Association for Thoracic Surgery

https://doi.org/10.1016/j.jtcvs.2018.10.088

Atrioventricular block (AVB) continues to be an important problem after congenital heart surgery. In this issue of the Journal, Romer and colleagues ${ }^{1}$ report on 15,901 patients who underwent cardiac surgery in 25 centers as part of the Pediatric Cardiac Critical Care Consortium (PC4) registry. They found that the incidence of postoperative AVB was $2.7 \%$ and that $1 \%$ of patients with postoperative AVB required a permanent pacemaker (PPM). Despite a laudable attempt, Romer and colleagues ${ }^{1}$ were not able to create a model with significant discriminatory ability to identify

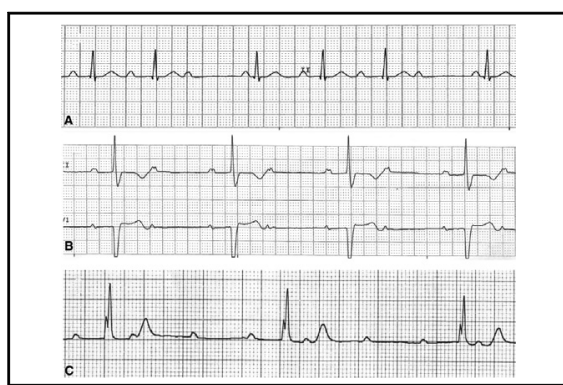

Types of second- and third-degree atrioventricular block.

\section{Central Message}

It is still unclear who will need a permanent pacemaker after congenital heart surgery, but waiting for return of atrioventricular conduction for more than 10 postoperative days is unwarranted.

See Article page 1168.
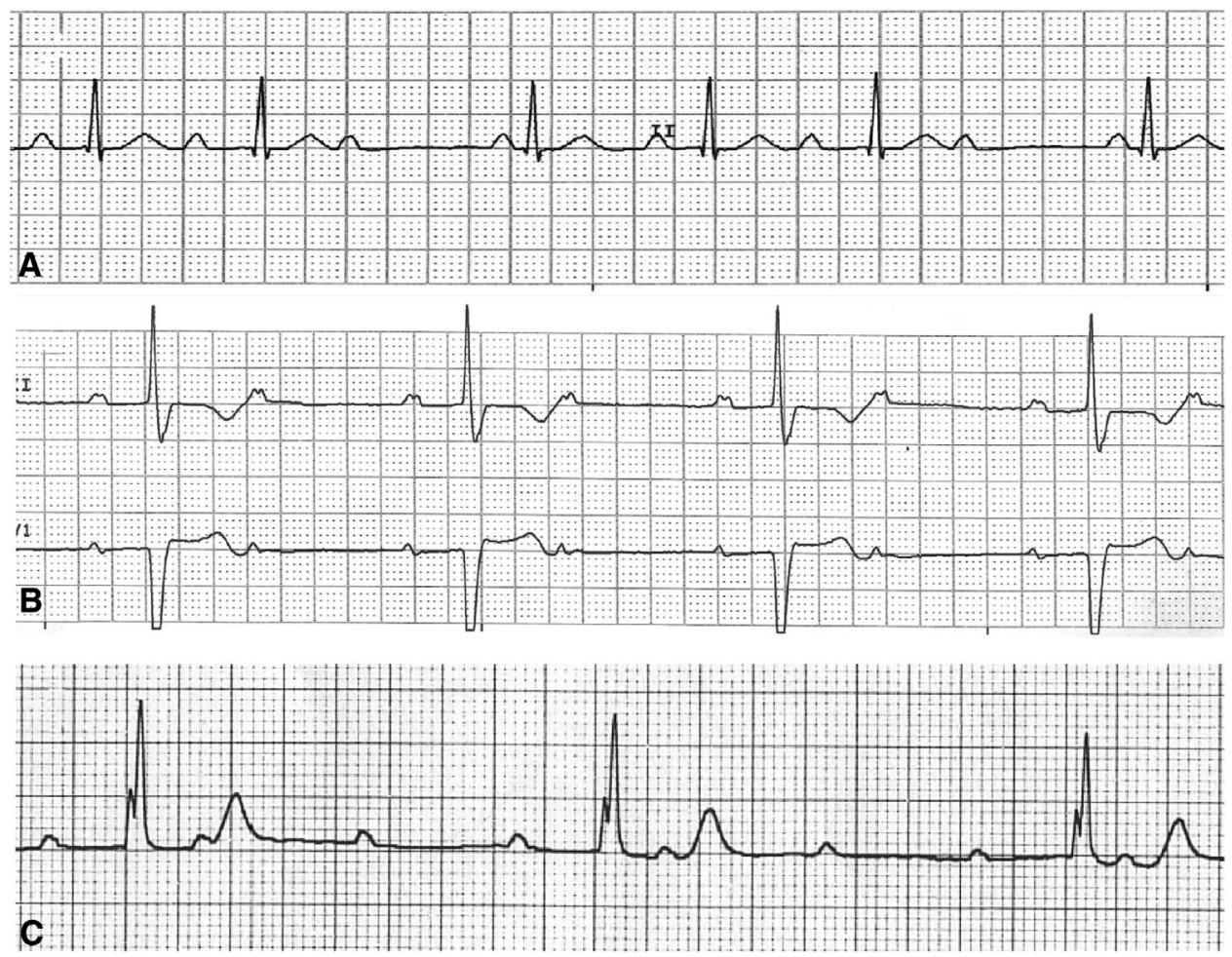

FIGURE 1. Different types of second- and third-degree atrioventricular block. A, Mobitz I (Wenckebach) second-degree atrioventricular block-the PR interval increases with every beat until a ventricular beat is dropped. B, Mobitz II second-degree atrioventricular block with 2:1 atrioventricular conduction. C, Complete heart block. 
which patients with postoperative AVB would benefit from PPM placement at the time of surgery.

The incidence of PPM placement varied widely between centers, from $0 \%$ to $6.3 \%$. Even though part of this variability may be a reflection of case mix, hospital volume, and clinical practices, one has to acknowledge that surgical technique likely plays a significant role.

Another striking finding of the study was that even though most guidelines suggest that a PPM be placed if atrioventricular conduction has not recovered after 7 to 10 days, ${ }^{2}$ only $62 \%$ of patients with AVB that required PPM had the device placed by 10 days. Because $94 \%$ of patients with transient AVB had recovered conduction by day 10, delaying placement of a PPM beyond that time frame is likely to incur unnecessary costs without a clear clinical advantage.

Transient postsurgical AVB is not completely benign. It is an incorrect assumption that patients who recover from AVB after surgery are clear from needing a PPM. In a recent study, Aziz and associates ${ }^{3}$ found that as many as $16 \%$ of patients with transient AVB after surgery may have late development of AVB. They found that a longer duration of transient AVB was associated with eventual development of AVB. These findings support the premise that waiting for recovery of $\mathrm{AV}$ conduction beyond 10 days is unlikely to be beneficial, even if some degree of AV conduction does indeed return later.

As part of their current study, Romer and colleagues ${ }^{1}$ defined postoperative AVB as "second- or third-degree AVB that was treated with critical care therapies." It is unclear whether the type of second-degree AVB was identified as part of the registry. This is important, because not all second-degree AVBs are considered high grade (Figure 1). The inclusion of patients with Mobitz I AVBs (who would likely recover atrioventricular conduction but are nonetheless treated in the critical care setting) may have contributed to the high chance of atrioventricular conduction recovery. If Romer and colleagues ${ }^{1}$ had included only patients with high-degree AVB, the number of affected patients would be lower, but the percentage of those patients requiring a PPM would likely be higher.

Despite the limitations inherent in a retrospective registry design, this study includes relatively accurate data from a very large number of patients throughout multiple institutions. As such, it provides important insights into the epidemiology of AVB after congenital heart surgery. Studies such as this will further our understanding and eventually allow us to determine which patients with AVB after congenital heart surgery are likely to require a PPM during their lifetimes.

\section{References}

1. Romer AJ, Tabbutt S, Etheridge SP, Fischbach P, Ghanayem NS, Mohan Reddy V, et al Atrioventricular block following congenital heart surgery: analysis from the pediatric cardiac critical care consortium. J Thorac Cardiovasc Surg. 2019;157:1168-77.

2. Epstein AE, DiMarco JP, Ellenbogen KA, Estes NA III, Freedman RA, Gettes LS, et al. American College of Cardiology Foundation; American Heart Association task force on practice guidelines; Heart Rhythm Society. 2012 ACCF/AHA/ HRS focused update incorporated into the ACCF/AHA/HRS 2008 guidelines for device-based therapy of cardiac rhythm abnormalities: a report from the American College of Cardiology Foundation/American Heart Association task force on practice guidelines and the Heart Rhythm Society. J Am Coll Cardiol. 2013;61: e6-75.

3. Aziz PF, Serwer GA, Bradley DJ, LaPage MJ, Hirsch JC, Bove EL, et al. Pattern of recovery for transient complete heart block after open heart surgery for congenital heart disease: duration alone predicts risk of late complete heart block. Pediatr Cardiol. 2013;34:999-1005. 